\title{
NEW MOMS USE OF MEDIA TECHNOLOGY IN PARENTING
}

\author{
${ }^{1}$ Cynthia Pui-Shan Lau \\ laups@utar.edu.my \\ Universiti Tunku Abdul Rahman \\ ${ }^{2}$ Hamedi Mohd Adnan, PhD \\ Universiti Malaya \\ ${ }^{3}$ Amira Firdaus, PhD \\ Universiti Malaya \\ Tarikh dihantar: 27 Mei 2021 / Tarikh diterima: 14 Jun 2021
}

\begin{abstract}
Abstrak Literature review from as early as 2004 till 2020 was analyzed from various databases such as Web of Science (WoS), SAGE Publications, Wiley-Blackwell, Elsevier, and ACM. These literature reviews were within the area of new media and new moms and their transition towards parenthood. Seeing that new moms are navigating ubiquitous territory of parenting coupled with isolation and insufficient face-to-face contact, more urban new moms are utilizing technology to obtain information and support. The researcher created three blocks of searches with keywords ranging from parenting, new media and social media groups to obtain these literatures. Pertinent literature was highlighted in this research. Results from combing the literature indicates that new moms are utilizing various types of technology to obtain information and support ranging from general internet search engines, bulletin boards, blogs and Facebook as these platforms provides the interactivity and ease of use for exchange of information as well as the sense of belonging to a community with shared interest.
\end{abstract}

Keywords: new media, new moms, parenting, social media

\section{INTRODUCTION}

The transition into parenthood begins from conception to postpartum and it is a long-term restructuring process from the time of birth till after birth (Donelle, et. al., $2021 \& \mathrm{McDaniel}$, Coyne \& Holmes, 2011). The demands of a young child pose substantial demands on a new family and a new mother (McDaniel, Coyne \& Holmes, 2011). It can be safely said that this is one of the most stressful periods in a woman's life which could bring a host of psychological and emotional challenges if not managed properly (Leigh \& Milgrom, 2008). During this period, resources are highly valued by new moms so as to navigate this challenging times and new responsibility (McDaniel, Coyne \& Holmes, 2011; Donelle, et.al.,2021).

In recent times, new moms can be seen to forge social connection with other moms in similar situations though internet-based media for emotional and informational support (Prabakhar, et.al., 2017). Since the early 2000s, mothers have had access to digital resources for information and support (Newhouse \& Blandford, 2016). These digital resources have evolved from the use of websites such as blogs (Newhouse \& Blandford, 2016), mobile phone apps (Lupton, 2016) to social media such as Facebook (Holtz, Smock \& Reyes-Gastelum, 2015). The internet has proven to empower women through information exchange and online communities and thus new moms have been receiving support and information to deal with the new responsibilities of being a new parent (Meadows, 2011). McDaniel, Coyne \& Holmes (2012) explained that social networking are new platforms for mothers to connect with one another and provides a "safe place" for interaction. This "safe place" is particularly important for new moms who may feel isolated from being tied to a schedule of a newborn.

Therefore, it is safe to say that social support is one of the most important factors in enhancing the wellbeing of a new mom (Alianmoghaddam, Phibbs \& Benn, 2018). Social support is vital in the role of assisting a new mom transition into parenthood especially in 
coping with the feeling of isolation when new mothers feel like they have been alienated or self-blame for not being able to live up to societal expectations (Alianmoghaddam, Phibbs \& Benn, 2018). This is particularly true in the aspect of breastfeeding for new mothers (Alianmoghaddam, Phibbs \& Benn, 2018; Robinson, et.al., 2019; Yasya, et.al., 2020). As breastfeeding is a source of nutrition for newborn infants, new moms are faced with breastfeeding challenges (Robinson, et.al., 2019) such as embarrassment in public feeding, returning to work challenges, lack of support from family and workplace and lack of apathy (Johnson, et.al., 2016). Such issues coupled with recovery of childbirth and adjustments to parenting can lead to depression and stress among new moms (Wachs et al., 2009; Archer \& Kao, 2018).

Lupton (2016) found that new moms are therefore turning to new media for information immediate, regular, detailed, practical, customized reassuring, unbiased and professional. In a recent research by Alianmoghaddam, Phibbs \& Benn (2018), a new generation of Gen Y moms are relying on online infant information. The research also found that mobile apps are a good option for promoting breastfeeding and that the strength of weak ties among social media members provides efficient non-judgmental peer support among new moms. Therefore, it is important to understand the new media technological uptake as a resource in facing the challenges as they navigate their way to being a new mom. This paper reviews new media usage among new moms by summarizing scholarly articles as well as identification of ideas and the need for future study.

\section{LITERATURE REVIEW}

\section{New Mothers and Parenting}

Women entering motherhood is often faced with challenges, uncertainties (Song et al., 2012; Crum, 2000) and a variety of mixed feelings like primal, joy, loneliness, physical stress, and psychological challenges (Hunting, 2004). Unlike women of our mother's generation, women of today are faced with so many choices when it comes to fertility, pregnancy and childbirth (Song et al., 2012).

This coupled with societal pressure to conform to social norms has put on tremendous pressure and stress on a new mother. Motherhood is seen as a major development in a person's life (Leahy-Warren et al., 2011); fraught with difficulties (Madge \& O'Connor, 2006); ambiguity (Hether, 2012); and disorientating (Holtz et al., 2015). As mentioned by Bartholomew et al. (2012), LeMasters (1957) was the first to identify and acknowledge that the transition into parenthood is one of the most difficult time in a person's life. The demands of a newborn child can be daunting and stressful (McDaniel et al., 2012; Qian \& Mao, 2010) where parents cope with exciting and yet confusing times (Crum, 2000).

This stress is further exemplified when first-time mothers are pressured to conform to cultural expectations and self-imposed expectations (Johnson, 2014; Song et al., 2012). Mothers with first babies who has little familiarity with small children will inevitably question their capabilities as new moms (Leahy-Warren et al., 2011) because they are unprepared for the difficult experience of being first time moms (Hunting, 2004). In addition, as someone who is negotiating a new phrase of life, mothers today are also seen as trying to adhere to parenting ideologies which was discovered by Hays (1996) as "intensive mothering" where a parent tries to acquire adequate knowledge in raising their child according to proper child development stages.

The term "intensive mothering" was initially used for stay-at-home-moms where mothers devoted their entire time in caring for their children and ensuring that the needs of their children is fulfilled. The concept of parenting as a cultural ideology was also recognized in Madge and O'Connor's (2006) research in which Valentine (1997) cited that the art of 
parenting has turned into a "cultural ideology" where the act of parenting is constantly changing over time.

However, in recent years, this term is also being adopted by full-time-working-moms who, though they are not around much during the day, they seek different ways in prioritizing their children's needs by providing for them economically (Walls et al., 2014). In Porter's (2008) research on Japanese and U.S mothers' concerns and expert advice, this was recognized as a "child-centered approach" to parenting where priority is given to the child's needs or desires.

It is further noted by Eriksson and Salzman-Eriksson, 2013) that a trend towards a more active parenting role where both fathers and mothers are involved in the up-bringing of their children. Today's parents are no longer satisfied with simple descriptions of parenthood (Plantin, 2009). Findings from Colorassi's (2007) study on parents' information needs points out that parents are looking out for information on skills and techniques, what is normal, and how to handle difficult situations.

In Marden and Nicholas's (1997) research where parents with children under 5 years old were being interviewed for parental needs for information and results from the data shows that parents' need for information were grouped by importance starting with healthcare, childcare, child development and education. A positive relation was seen between mother's knowledge and their child's development by various research findings (Benasich \& BrooksGunn, 1996; Miller et al., 1991; Stevens, 1984; Stoiber \& Houghton, 1993; Veddovi et al., 2004) which points out that mothers of today are playing an active role in their child's life (Eriksson \& Salzman-Eriksson, 2013).

This was also noted by Colarossi (2007) where parents of children between 3 to 5 years old was seen interested in categories such as handling risky or unwanted behaviour; social interaction; communicating with a child; moral development; mental ability; and finally, emotional development. However, in his research, little was known of available sources of information to address the needs of new parents.

Therefore, he adopted a qualitative study employing three qualitative assessments which resulted in three general types of information needs required by new parents. They are typically skills and techniques; information on normalities and how to handle difficult and challenging situations. Similarly, Marden and Nicholas (1997) identified several areas which were of interest to parents with children below the ages of 5 years old.

They were health care; childcare; child development; schools; behaviour; education; and financial planning. In their research, participants actively gathered information from health care organizations, professionals, friends, and printed materials. Interviews were held with 35 new parents in London.

With past research findings, it is sufficient to say that mothers are seen adapting to current changes, which differs from those of their previous generations (Madge \& O'Connor, 2006) where parents of today are seen to actively seeking parenting information. According to Madge and O'Connor's (2006) research, it indicates that new families are living further away from their relatives and this makes it difficult to gather support. Therefore, new mothers were seen to be referring to the Internet to adjust to the transition to motherhood. It was also noted in the research that new mother's value shared experiences from other new moms. A reasonable explanation for this change could be that "mothering practices is being renegotiated over time" (Holloway, 1999:92) and raising children in this day and age is entirely different from to that of previous generations due to economical/technological or socio/historical changes (Valentine, 1997). Valentine's findings were in line with Porter and Ispa's (2012) research where mothers of children between 0 to 2 year olds participated in a survey on two popular parenting magazine websites on questions about parenting infants and toddlers. 
Findings from the research suggests that concerns, ranging from sleep patterns to breastfeeding, which were posted on the website reflected a wide range of parenting beliefs and approaches. In part, this could be due to frequent intercultural contacts and varied opinions and information on parenting publications as some of these views originates from other countries.

All in all, the transition into parenthood is a long-term process which changes according to the child's age from birth till after birth (McDaniel et al., 2012). To add to the stress of managing and adjusting to a role of being a parent, mothers are also faced with another challenge where an increase in female participation in the workforce has inadvertently affected their roles as childcare providers (Subramaniam, Ali \& Overton, 2010). In 2011, the Organization for Economic Co-operation and Development released its report citing that both men and women in the Asia/Asia Pacific region spend an average of 6 hours a day at work (OECD, 2012).

In Arendell's (2000) findings when analysing a decade's worth of literature from 1990 to 2000 discovered that over the past 30 years, employment rate for females has increased by three-folds across all racial and ethnic groups in North America. However, in South East Asia, similar findings were recorded by a survey conducted by the International Labor Organization in 2012 where participation in female labor was found to be historically higher due to improvement in education and a shift to an export-oriented industry (Verick, 2014). Similarly, in Malaysia, 58.1\% of female population are married with full time employment were between 30 to 39 years old (Subramaniam, Ali \& Overton, 2010) where, according to Malaysian Employment Act 1955, an average work week consist of a maximum of 8 hours per day for a maximum of 6 days per week. In 2012, a Malaysian local daily, The Star, reported that a survey conducted by Expedia shows that Malaysians are ranked fourth among the world's top workaholics (thestar.com.my, 2012). From the above, it is safe to say that working mothers are constantly challenged between parenting duties and the working world (Crowley, 2014).

Recent research conducted by Budds et al., (2017) suggests that parenting is particularly important in a child's early years of life. Proper sensory stimulation is required to ensure a child's cognitive development is appropriately fascilitated. Three main themes were identified in this research to enable appropriate child cognitive development. They are mothers as committed facilitators, mothers as creative provider and mothers as caring monitor. This proves that a mother's role in early childhood days is vital and strongly suggests that new mothers uphold to parenting ideologies such as intensive mothering while adopting a child-centred approach to promote a healthy child.

In summary, with new mothers facing challenges and uncertainties (Song et al., 2012; Crum 2000); psychological challenges coping with being a parent (Hunting, 2004); ambiguity of the idea and notion of parenting (Hether, 2012) coupled with longer working hours (OECD, 2012) has caused more parents to turn to the internet for support and information on parenting (Doty \& Dworkin, 2014; Madge \& O'Connor, 2004). Therefore, the following section will review new mothers' reason for seeking parenting information online and new media trends.

\section{New Mothers' use of New Media}

Internet usage is increasing compared to 2013 where a median usage of $41 \%$ across developed and developing countries have risen to 54\% in 2015 (Pew Research Center, 2016). According to its report, much of the increase came from emerging markets such as Malaysia, Brazil and China (Pew Research Center, 2016). The increase is also partly contributed by the increase in smartphone ownership which makes accessing the internet easier (Pew Research Center, 2016). In its survey, $76 \%$ of adult internet users were reported to using social media such as Facebook and Twitter (Pew Research Center, 2016). With this in mind, it is important to realize that among the millions of internet users, parents are a group of users that utilises the internet for 
various purposes such as information seeking and decision making (Reuter, 2006). General forms of Internet usage may vary from emails, chat rooms, bulletin boards and search engines (Reuter, 2006). As with technology, a recent look at the literature from 2006 to 2015 suggests that Internet usage trends among parents is evolving from Emails, search engines, online message boards (Porter, 2008; Qian \& Mao, 2010; Reuter, 2006; Song et al., 2012) to blogs, online support groups and social networking sites like Facebook (Asiodu et al., 2015; Gibson \& Hanson, 2013; Holtz, Smock \& Reyes-Gestelum, 2015; Morris, 2014; Schellinger, 2012; Song et al., 2012; Stern, Cotton \& Drentea, 2012).

Facebook continues to be the most widely used social networking site (Nielsen, 2012) and a new group of users have emerged from Nielsen's 2012 report - mothers (Nielsen, 2012). As of December 2015, Facebook has recorded 1.04 billion active users daily (Facebook Newsroom, 2016) Past research concluded that Facebook was used by mothers for information seeking, support for breastfeeding, and for seeking advice (Bernhardt \& Felter, 2004; Drentea \& Moren-Cross, 2005; Madge \& O'Connor, 2006). Bartholomew et al. (2012) stated that the majority of Facebook users are aged between 18-24 and 35-54 years old. Therefore, it is safe to say that prime users are in their childbearing years and could possibly fall under the category as transitioning into parenthood (Bartholomew et al., 2012). The recent shift in social structure has resulted in mothers turning to online parenting groups for support and advice (Asiodu et al., 2015; Bartholomew, 2012; Holtz, Smock \& Reyes-Gestelum, 2015; Kauffman, 2014; McDaniel et al., 2012; Schellinger, 2012). The popularity of online parenting groups is increasing because of shared interest within its group members allowing members to exchange information and support despite geographical differences (Madge \& O'Connor, 2006). Therefore, this section of the literature review documents the various usage of new media in online groups by mothers when transitioning into parenthood.

In 2006, Reuter's research on parent's internet usage suggests that the most common functions used for seeking information were emails, forums/bulletins and the World Wide Web. Common search topics includes medical, nutrition, milestones, child safety, discipline and communication. It is interesting to note that majority of Reuter's respondents were parents with single child (Reuter, 2006). This might suggest that first time parents are heavily reliant on the internet for seeking information (Reuter, 2006). Between the years 2008 to 2010, there seem to be a shift in internet trend from emails or search engines to online bulletins and blogs (Porter, 2008; Qian \& Mao, 2010). Again, this heavy reliant on online bulletins and blogs is due to the decrease in network support from family members (Davis \& Greenstein, 2004). Online bulletins were heavily researched between 2008 to 2012 (Porter, 2008; Qian \& Mao, 2010 \& Song et al., 2012). In 2008, Porter researched on the comparisons between Japanese mothers versus Western mothers on parenting online bulletin boards. Among the areas of concern for both mothers are infant or toddler nutrition; sleep problems; development; disobedience; toilet training; and separation anxiety (Porter, 2008). The research also highlights the cultural differences between Asian and Western mothers and how parenting practices of the West influence Asian parenting styles (Porter, 2008).

Similar research was done by Qian and Mao (2010) on overseas Chinese women living in the United States who is dependent on online bulletin boards moderated by Chinese women living overseas. These bulletin boards are specifically for pre-natal and post-natal women. In its findings, popular areas of discussion are baby pictures; pregnancy journal; baby development journal; delivery experiences; medical issues; baby products; maternity products; doctors; work-life balance; and how to conceive (Qian \& Mao, 2010). It was also discovered that women on these online boards were using it as a platform for self-expression rather than for support.

The trend of mothers utilizing online bulletin boards was also seen in 2012 where women were using these bulletin boards to manage their pregnancies and obtain reassurance 
from members on the medical decisions that they make (Song et al., 2012). The year 2012 was also the beginning of a new trend of blogging and social networking (particularly Facebook and Twitter) among mothers (Asiodu et al., 2015; Holtz, Smock \& Reyes-Gestelum, 2015; McDaniel, Coyne \& Holmes, 2012; Morris, 2014; Schellinger, 2012). Blogging and Facebook was used as a platform for new mothers with babies below 18 months to connect with family members and friends for social support to assist in connectedness (McDaniel, Coyne \& Holmes, 2012). It is interesting to note that mothers feel more connected to blogging compared to social media use (McDaniel, Coyne \& Holmes, 2012). This could probably be due to mothers utilizing blogs as a platform for documenting their parenting journey with family and friends while social media was used for "keeping updated" on other people's lives (McDaniel, Coyne $\&$ Holmes, 2012). The mothers in the research also indicated that they felt that blogs were followed by people who are closest to them and therefore feel more connected with comments from blogs as compared to social media. Therefore, it is safe to say that mothers feel more connected via blogs compared to social media (McDaniel, Coyne \& Holmes, 2012).

Similarly, within the same year of 2012, parenting and media trends were also pointing towards the formation of online groups and social networking sites (Asiodu et al., 2015; Gibson \& Hanson, 2013; Holtz, Smock \& Reyes-Gestelum, 2015; Morris, 2014; Schillinger, 2012). It is noted that online groups are formed for people facing similar challenges or situations (child disabilities, illnesses etc...) to interact with each other by sharing information and support (Schellinger, 2012). Although Schellinger's (2012) research centred around online support groups for parents with children with ADHD (Attention Deficit Hyperactive Disorder), findings in the research suggests these online support groups assists in obtaining information on ADHD; available treatments that is offered; and to connect with other parents who is faced with similar challenges. Gibson

and Hanson's (2013) research supports previous researchers in terms of understanding motherhood and technological use where mothers use technology such as Facebook to seek advice on development stages; feeding; and health concerns. This is particularly spurred by the growth of smartphone usage where mothers can now access the internet via their phones which is convenient instead of powering up their laptops or computer to be online (Gibson \& Hanson, 2013). In 2014, research on mothers use and social networking sites was still relatively small and growing (NielsenWire, 2012; Balaam et al., 2013). As claimed by Morris (2014) to be one of the pioneers in researching mothers (with child younger than 3 years old) use of Facebook in terms of perceptions towards sharing information and content about their child. Findings from Morris's (2014) study found that mothers uses Facebook seek social support; advice, parenting purposes; social interaction, favors; birth announcements; and for sharing milestones. However, it is important to note that Morris's work was centred around the mother's personal Facebook wall and not on a Facebook parenting group.

Another research done by Holtz, Smock and Reyes-Gestelum (2015) expanded on parenting Facebook usage relating to motherhood. Findings from the research suggests that mothers use of Ask the Chicks Facebook page for relaxation; expressive information sharing; escapism; social interaction and information seeking (Holtz, Smock \& Reyes-Gestelum, 2015). Within the same year, Asiodu et al. (2015) researched on breastfeeding and use of social media among first-time African American mothers in the United States. Though the research wasn't intended on a particular social media platform but there were repeated mentions of Facebook, Google, YouTube, Mom365, and WebMD from its participants. Findings suggests that participants use social media for social support and search for pre-natal and parenting information (Asiodu et al., 2015). However, the research also suggests that once the child grows, mothers found it difficult to recall on breastfeeding information. The research also states that social media is an important platform for dissemination of breastfeeding information for 
African American mothers. However, it is suggested that the platform be fully utilized to explore mobile health interventions.

In 2018, research was conducted by Baker and Yang on new mothers use of new media in the United Kingdom. From their research, it shows that new mothers rely on social media to communicate with other new mothers as well as for information and social support. The research also indicates that healthcare providers should utilize social media to assist new mothers in terms of social support and resources. The study also concludes that the ubiquity of online parenting social networking sites contributes as an important pillar of social support for new mothers as well as working mothers and mothers who lives far away from their immediate families. Similarly, Price et al., (2018) was researching into new mothers' seek of information during the first six months of birth. Price's research also suggests that new mothers valued social media to establish peer-to-peer connections for support. A 2019 research was also conducted by Regan and Brown (2019) on new mothers across the United Kingdom, United States of America, and Australia. The research was on breastfeeding support which is integral for a new mom. It was noted from the research that the United Kingdom has a pro-formula milk culture and therefore it was challenging for new moms to gain emotional support and information on breastfeeding practices. Findings from Regan and Brown (2019) found that women are turning to online support groups for information, reassurance and a sense of belonging. Findings also suggests that mothers turn to online support due to lack of professional and family support. However, within these groups, Regan and Brown (2019) also discovered that appropriate moderation should be conducted to ensure its members are not judged and that information is accurate, and members should respect one another.

Subsequent study done by Virani et al., (2020) also supports the development of mobile applications by healthcare providers to provide a link between the healthcare services and new mothers. The research was done across members of online parenting groups in Canada and suggested that developers investigate developing mobile applications for parenting resources.

Online support groups via Facebook have been a constant form of new media used by new moms. This was found in several recent findings from Yasya, et. al., (2019), Mansour (2020), and Skelton, Evans \& LaChenaye (2020). Yasya, et. al. (2019) found that positive breastfeeding behavior among new moms was found through social media, in particular Facebook support groups. In terms of general parenting practices and opinions, mothers from Mansour's (2020) research supported the notion that sharing information among other women with a common ground despite coming from different backgrounds prove that participation within the group is beneficial and engaging in information seeking among new moms. Meanwhile, Skelton, et.al. (2020) confirms that new moms were found to be utilizing online parenting group on Facebook to promote interaction and breastfeeding practices which could impact breastfeeding knowledge.

\section{METHODOLOGY}

Initial search was conducted via Google Scholar Search using phases such as "parenting and online groups", "Facebook online parenting groups", "parenting and new media", "new media and parenting online community", "social media and parenting", "Facebook groups on parenting", and "Facebook breastfeeding groups". The strategy for this article was to include as many articles as possible on parenting and new media. Therefore, the researcher has developed a block chart to include all sub terms as showed in Table 1. The literature review for this research has a vast expanse starting from the late 90 s to 2020 and highlights the media technology trends of new mothers in assisting them in the transition to motherhood. Relevant scholarly articles were extracted from Google Scholar and another round of search was conducted via the Universiti Malaya digital library services. References for this paper was 
selected from databases such as Web of Science (WoS), SAGE Publications, Wiley-Blackwell, Elsevier, and ACM. Articles were then filtered to the most relevant for this research of new moms use of media technology in parenting and saved using Mendeley.

Table 1: Terms used in search for scholarly articles for new moms use of media technology in parenting

\begin{tabular}{cccc}
\hline Database & Block 1 & Block 2 & Block 3 \\
Web of & \#parenting & \#Online groups & \\
Science & \#breastfeeding & \#Online & \#Block 1 and Block 2 \\
SAGE & parenting & communities & \#groups \\
Wiley- & \#general parenting & \#new moms & \#communities online \\
Blackwell & \#new parents & \#Facebook group \\
Elsevier & \#parenthood & \#Facebook parenting \\
ACM & group \\
& & \#support group \\
& & \#new media \\
& & \#social media groups \\
& & \#new media use \\
& &
\end{tabular}

\section{LITERATURE REVIEW FINDINGS AND DISCUSSION}

\section{Overview of new media usage among new moms}

Several themes were identified when combing through the literature review and new moms new media usage was seen to be on a uptake trending from internet search engines, electronic bulletin boards, mummy blogs and social media (Valtchanov, et.al., 2016; Moon, et.al., 2019). In the past, guidance and support for new moms were traditionally given by family and friends. However, with the rapid use of the internet and social media, new moms are turning to new technology for support and information while transitioning to motherhood (Baker \& Yang, 2018). Several reasons were also identified pertaining new moms use of new media. The main themes are (1) parenting, (2) information and (3) support. The findings from this research will then breakdown the various sub-themes according to the various types of new media.

\section{Internet search engines}

Early stages of new moms use of new media indicates that basic internet search was widely used for information and support. While most of these are middle-class moms who has access to technology such as personal computers and the internet. Due geographic factors of new families living away from the support of family and friends, it was found that new moms were turning to basic search engines such as Google.com for their searches. Upon viewing of the displayed results, these new moms would then filter the websites based on credibility. An interesting finding was that new moms were also on the lookout on whether these websites are maintained by professionals or by user-generated content. The literature also confirms that several pertinent websites such as WebMD, Babycenter.com and Mayo Clinic was favorable among new moms (Barkhuus, Bales \& Cowen, 2017) for information on their pre-natal and newborn infants.

Findings from several research found that seeking health information on the internet was second nature to new moms (Sundstrom, 2015). As Plantin and Daneback (2009) suggests, preliminary internet search engines were used to as information centers and support for new 
moms as these searches garners a broad range of resources where users could actually combine information to cater to their informational needs. It is also reported that health-related topics are top priority for moms during pregnancy especially in fetal development. Once the child is born, searches are defined towards baby development, baby's health, breastfeeding and information on upbringing (Bernhardt \& Felter, 2004; Mankuta, et.al., 2007; O'Connor \& Madge, 2006). It can be concluded that many new parents deem the information searches on the internet as a first-point of reference before seeking further advice from other sources such as healthcare professionals, family or friends (Plantin \& Daneback, 2009).

\section{Bulletin Boards}

One of the early online communities for parenting was developed in the form of bulletin boards whereby discussions take place in a virtual environment enabled by asynchronous communication (Lee, 2012). Early research on bulletin boards was done by Madge \& OConnor (2004). Findings from this research indicates that new moms use bulletin boards for knowledge and support. This is because these bulletin boards serve as a platform for exchange of information between healthcare professionals as well as other mothers. Bulletin boards also acts as a forum that provides a space for sharing of information with updated advice daily. New moms were likely to use these informal sources for information related to milestone knowledge (Elliot \& Virginia, 2007). Findings from Qian \& Mao (2010) also found that bulletin boards were used to giving and seeking support. In their research, several areas of interest were highlighted such as health, good news sharing, nutrition \& diet and posting of baby photos.

\section{Blogs}

A study published in 2017 by McGannon, McMahon \& Gonsalves mentioned that blogs are nonintrusive where participants use to construct their own identities. Similarly, a study by Haslam \& Baker (2017) mentioned that blogs are the third most used social media platform for new moms to obtain information. Findings from the literature suggests that blogs were often used by new moms to (1) search for parenting information, (2) obtain parenting advice (3) seeking advice for child behavior (4) sharing of positive experiences and (5) feeling of connectedness. Blogs was also found to be used for gap-bridging activities for informationseeking behaviors. Gap-bridging is an action of collective sense-making constructed by parents when seeking information. These includes using blogs to seek information for (1) resolving conflicting parenting advice and (2) checking if child behavior is normal. According to Jang, Dworkin \& Hessel (2015), most gap-bridging activities that happens on blogs starts out as problem identifiers where parents would use blogs as a venue for interaction with other parents.

\section{Facebook}

Bartlett, Guzman \& Ramos-Olazagast (2018) states that Facebook is one of the most used social media platforms by new moms for information, support and guidance. Breastfeeding was the main discussion area in Facebook groups where new moms are often seen seeking for breastfeeding support because of its community, immediate, complementary and informative nature (Bridges, 2016). Similar findings were also seen in Skelton's (2018) research where Facebook usage was high with breastfeeding moms where it is used as a platform for normalizing breastfeeding, empowerment of knowledge, resource, shared experiences and a sense of community. Combing of the literature also found that as Facebook's platform encourages interactive communication exchange between its members and therefore facilitates more effective diffusion of innovation of ideas among its members (Yasya, et.al., 2020). While not only supporting new moms in their breastfeeding journey but Facebook was also found to be a source for social connections in times of isolation from being a first-time mother, not 
wanting to "miss out" on news, access to information, stalking people as well as following of influencers and organizations.

\section{CONCLUSION}

The contribution of this research is to identify the uses and adoption of new media technology among new moms as well as the technological trends from general search engine searches, bulletin boards, blogs to Facebook. The literature was sourced from more than 10 years which indicates that new moms are utilizing technology as well as adopting newer technology to assist them in navigating this ubiquitous period of their lives as they embark on this new journey called parenting.

This literature review does have its limitations one of which are that the literature is focused on breastfeeding moms from Western countries such as Australia, United States and the United Kingdom. Though general parenting was also discussed but emphasis on parenting challenges were very much skewed towards challenges of breastfeeding moms. For future research, it would be welcoming to conduct more research on Asian new moms as Asian moms could provide a more diversified research results due to cultural background and differences compared to their Western counterpart. As mentioned by Hossin (2018), interpersonal relationships are vital not only in physical support but emotional support. Research should also focus on the effectiveness of online parenting groups to determine new moms from these groups actually do apply the knowledge that they acquire from the online groups or sources or would they rather cross-check with healthcare professionals.

\section{REFERENCES}

Alianmoghaddam, N., Phibbs, S., \& Benn, C. (2019). "I did a lot of Googling": A qualitative study of exclusive breastfeeding support through social media. Women and Birth, 32(2), 147-156. https://doi.org/10.1016/j.wombi.2018.05.008

Archer, C., \& Kao, K. T. (2018). Mother, baby and Facebook makes three: does social media provide social support for new mothers? Media International Australia, 168(1), 122139. https://doi.org/10.1177/1329878X18783016

Asiodu, I. V., Waters, C. M., Dailey, D. E., Lee, K. a., \& Lyndon, A. (2015). Breastfeeding and use of social media among first-time African American mothers. Journal of Obstetric, Gynecologic, \& Neonatal Nursing, 44(2), 268-278. doi:10.1111/15526909.12552

Benasich, A. A., \& Brooks-Gunn, J. (1996). Maternal attitudes and knowledge of childrearing: Associations with family and child outcomes. Child Development, 67, 11861205

Bîră, M., Buzoianu, C., \& Tudorie, G. (2020). Social Support Mediated by Technology. A Netnographic Study of an Online Community for Mothers. Romanian Journal of Communication and Public Relations, 22(2), 57. https://doi.org/10.21018/rjcpr.2020.2.300

Baker, B., \& Yang, I. (2018). Social media as social support in pregnancy and the postpartum. Sexual and Reproductive Healthcare, 17(September 2017), 31-34. https://doi.org/10.1016/j.srhc.2018.05.003

Barkhuus, L., Bales, E., \& Cowan, L. (2017). Internet Ecologies of New Mothers: Trust, Variety and Strategies for Managing Diverse Information Sources. Proceedings of the 50th Hawaii International Conference on System Sciences (2017), 2283-2292. https://doi.org/10.24251/hicss.2017.276 
Bernhardt JM, Felter EM (2004). Online Pediatric Information Seeking Among Mothers of Young Children: Results from a Qualita- tive Study Using Focus Groups. Journal of Medical Internet Research. 1:e7.

Bartlett, J. D., Guzman, L., \& Ramos-Olazagasti, M. A. (2018). Parenting Knowledge among First-time Parents of Young Children Parenting Knowledge among First-time Parents of Young Children A Research-to-Practice Brief. Child Trends, July, 2018-2046.

Bridges, N. (2016). The faces of breastfeeding support: Experiences of mothers seeking breastfeeding support online. Breastfeeding Review: Professional Publication of the Nursing Mothers' Association of Australia, 24(1), 11-20. http://www.ncbi.nlm.nih.gov/pubmed/27188074

Crum, J. A. (2000). The whole nine months and then some. Health care on the Internet, 4(23), 99-111. doi:10.1300/J138v04n02 09

Donelle, L., Hall, J., Hiebert, B., Jackson, K., Stoyanovich, E., LaChance, J., \& Facca, D. (2021). Investigation of digital technology use in the transition to parenting: Qualitative study. JMIR Pediatrics and Parenting, 4(1), 1-10. https://doi.org/10.2196/25388

Daneback, K., \& Plantin, L. (2008). Research on parenthood and the Internet: Themes and trends. Cyberpsychology: Journal of Psychosocial Research on Cyberspace, 2(2), Article 2. https://cyberpsychology.eu/article/view/4213/3255

Davis, S. N. \& Greenstein, T. N. (2004). Cross-national variations in the division of household labor. Journal of Marriage and Family, 66, 1260-1271.

Eriksson, H., Salzmann-Erikson, M. (2013). Supporting a caring fatherhood in cyberspace An analysis of communication about caring within an online forum for fathers. Scandinavian Journal of Caring Sciences. 27; 63-69. doi:10.1111/j.14716712.2012.01001.x

Elliott, N. L., \& Virginia, W. (2007). First-Time Mothers' Parenting Knowledge during their Infant's First Year: Relations with Information Sources, Social Support Networks, Maternal Self-Efficacy, and Infant Development.

Gibson, L., \& Hanson, V. L. (2013). 'Digital motherhood': how does technology support new mothers. In CHI '13: Proceedings of the SIGCHI Conference on Human Factors in Computing Systems (pp. 313-322). Association for Computing Machinery. https://doi.org/10.1145/2470654.2470700

Holtz B, Smock A, \& Reyes-Gastelum D. (2015). Connected Motherhood: Social Support for Moms and Moms-to-Be on Facebook. Telemedicine and e- Health. May;21(5):415-21

Hunting, V.S. (2004). Social support for new mothers: an exploration of new mothers' postpartum experiences with online and offline peer support environments [MA Dissertation, School of Child and Youth Care, University of Victoria]. Dissertations and Thesis Database. University of Victoria, Canada.

Hether, H.J. (2012). Social media and health: Social support and social capital on pregnancyrelated social networking sites (usctheses-m2715) [PhD Thesis, Faculty of The Graduate School, University of Southern California]. USC Digital Library.

Hays, S. (1996). The cultural contradictions of motherhood. New Haven, CT: Yale University Press.

Holloway, S. (1999). Reproducing motherhood. In Laurie, N., Dwyer, C., Holloway, S. \& Smith, F. (eds) Geographies of new femininities (pp. 91-112). London: Pearson Education.

Holtz, B., Smock, A., \& Reyes-Gastelum, D. (2015). Connected motherhood: Social support for moms and moms-to-be on Facebook. Telemedicine and E-Health, 21(5), 150209114309005. doi:10.1089/tmj.2014.0118 
Haslam, D. M., Tee, A., \& Baker, S. (2017). The Use of Social Media as a Mechanism of Social Support in Parents. Journal of Child and Family Studies, 26(7), 2026-2037. https://doi.org/10.1007/s10826-017-0716-6.

Hossin, A.,(2018). Hubungan Interpersonal Sebagai Pengukuhan Jaringan Sosial Dalam Kalangan Komuniti Bajau Laut Di Semporna, Sabah. Jurnal Komunikasi Borneo, 6, 3037.

Johnson, A. M., Kirk, R., Rooks, A. J., \& Muzik, M. (2016). Enhancing breastfeeding through healthcare support: Results from a focus group study of African American mothers. Maternal and Child Health Journal, 20(S1), 92-102. doi:10.1007/s10995016-2085-y

Jang, J., Dworkin, J., \& Hessel, H. (2015). Mothers' use of information and communication technologies for information seeking. Cyberpsychology, Behavior and Social Networking, 18(4), 221-227. https://doi.org/10.1089/cyber.2014.0533

Leigh, B., \& Milgrom, J. (2008). Risk factors for antenatal depression, postnatal depression and parenting stress. BMC Psychiatry, 8, 24-35.

Lupton, D. (2016). The use and value of digital media for information about pregnancy and early motherhood: A focus group study. BMC Pregnancy and Childbirth, 16(1), 1-10. https://doi.org/10.1186/s12884-016-0971-3

Leahy-Warren, P., McCarthy, G., \& Corcoran, P. (2011). First-time mothers: Social support, maternal parental self-efficacy and postnatal depression. Journal of Clinical Nursing, 21(3-4), 388-397. https://doi.org/10.1111/j.1365-2702.2011.03701.x

Lee, E. (2012). Digital diaspora on the web: The formation and role of an online community of female Korean im/migrants in the U.S. [PhD Dissertation submitted to the Graduate School-New Brunswick Rutgers, The State University of New Jersey]. ProQuest Dissertations and Theses.

Meadows, S. (2011). The association between perceptions of social support and maternal mental health: A cumulative per- spective. Journal of Family Issues, 32, 181-208.

Madge, C., \& O'Connor, H. (2006). Parenting gone wired: Empowerment of new mothers on the internet? Social and Cultural Geography, 7(2), 199-220.

https://doi.org/10.1080/14649360600600528

Marden, M., \& Nicholas, D. (1997). The information needs of parents. Child Language Teaching and Therapy, 13(3), 279-285

Morris, M. R. (2014). Social networking site use by mothers of young children. In Proceedings of the ACM Conference on Computer Supported Cooperative Work, CSCW (pp. 1272-1282). New York. https://doi.org/10.1145/2531602.2531603

Mansour, A. (2020). Shared information practices on Facebook: The formation and development of a sustainable online community. Journal of Documentation, 76(3), 625-646. https://doi.org/10.1108/JD-10-2018-0160

McGannon, K. R., McMahon, J., \& Gonsalves, C. (2017). Mother running in the blogosphere: A discursive psychological analysis of online recreational athlete identities. Psychology of Sport and Exercise, 28, 125-135. Orton-Johnson.

Newhouse, N., \& Blandford, A. (2016). "My Facebook is a bit of a multiple personality at the minute": Social Media and the Transition to New Motherhood. NordiCHI, November.

Priel, B \& Besser, A., (2000). Dependency And Self-Criticism Among First-Time Mothers : The Roles Of Global And Specific Support. Journal of Social and Clinical Psychology, 1(4), 437-450.

Prabhakar, A. S., Guerra-Reyes, L., Effron, A., Kleinschmidt, V. M., Driscoll, M., Peters, C., Siek, K. A. (2017). "let me know if you need anything": Support realities of new 
mothers. ACM International Conference Proceeding Series, 31-40. https://doi.org/10.1145/3154862.3154863

Porter, N. \& Ispa, J.M. (2013). Mothers' online message board questions about parenting infants and toddlers. Journal of Advanced Nursing 69(3), 559-568. doi:

10.1111/j.1365-2648.2012.06030.x

Poushter, J. (2016). Smartphone ownership and internet usage continues to climb in emerging economies. Pew Research Center. https://www.pewresearch.org/global/2016/02/22/smartphone-ownership-and-internetusage-continues-to-climb-in-emerging-economies/

Qian, Y., \& Mao, Y. (2010). A content analysis of online social support behaviors of overseas Chinese prenatal and postnatal women. China Media Research. 6(4), 43-55.

Robinson, A., Lauckner, C., Davis, M., Hall, J., \& Anderson, A. K. (2019). Facebook support for breastfeeding mothers: A comparison to offline support and associations with breastfeeding outcomes. Digital Health, 5, 205520761985339. https://doi.org/10.1177/2055207619853397

Reuter, J.C (2006). Parent Internet Usage (UMI 1440754). [Master of Arts Dissertation, Department of Family \& Child Ecology, Michigan State University]. ProQuest Information and Learning Company.

Song, F. W., West, J. E., Lundy, L., \& Dahmen, N. S. (2012). Women, pregnancy and health information online: the making of informed patients and ideal mothers. Gender \& Society, 26 (5), October 2012, 773-798. DOI: 10.1177/0891243212446336

Stevens, J. H. (1984). Child development knowledge and parenting skills. Family Relations, $33,237-244$.

Stoiber, K. C., \& Houghton, T. G. (1993). The relationship of adolescent mothers' expectations, knowledge, and beliefs to their young children's coping behavior. Infant Mental Health Journal, 14, 61-79.

Schellinger, K.B. (2012). Internet support groups for parents of children with ADHD: An examination of the characteristics of group members and the impact of social support on parent functioning. (UMI 3526354) [PhD Dissertation, School of Education Loyola University Chicago]. UMI Dissertation Publishing.

Skelton, K., Evans, R., \& LaChenaye, J. (2020). Hidden communities of practice in social media groups: Mixed methods study. JMIR Pediatrics and Parenting, 3(1). https://doi.org/10.2196/14355

Sundstrom, B. (2016). Mothers “ Google It Up :" Extending Communication Channel Behavior in Diffusion of Innovations Theory Mothers “ Google It Up :” Extending Communication Channel Behavior in Diffusion of Innovations Theory. 0236(February). https://doi.org/10.1080/10410236.2014.936339

Winter, J. (2017). Parenting identities, practices and social support in popular parenting websites $\mathrm{PhD}$ 2017. Thesis.

Wachs TD, Black MM and Engle PL (2009) Maternal depression: a global threat to children's health, development, and behavior and to human rights. Child Development Perspectives 3(1): 51-59.

Walls, J. K., Helms, H. M., \& Grzywacz, J. G. (2014). Intensive Mothering Beliefs Among Full-Time Employed Mothers of Infants. Journal of Family Issues, 37(2), 245-269. https://doi.org/10.1177/0192513X13519254

Yasya, W., Hardinsyah, Muljono, P., \& Seminar, K. B. (2020). Online Social Support Communication of Breastfeeding Mothers on Facebook Group. 436, 424-428. https://doi.org/10.2991/assehr.k.200529.088 